\title{
Sector forestal-celulosa, agricultura de secano e industria en el Gran Concepción: ¿encadenamiento productivo o enclave?
}

\author{
Gonzalo Falabella G. y Francisco Gatica N.
}

RESUMEN

Se aborda el binomio cadenas productivas y territorio, identificándose dos tipos de desarrollo: el "enclave" del Secano Interior y el de "encadenamiento potencial" entre dicho enclave y la Conurbación del Gran Concepción. Los beneficios de la cadena productiva forestal-celulosa, de importancia mundial, no llegan a su territorio, que permanece en la precariedad. El Gran Concepción, segunda conurbación industrial de importancia nacional, no logra conectarse virtuosamente con su entorno cercano mediante sus redes económicas, ni tampoco con la cadena forestal-celulosa del Secano Interior. El artículo se basa en datos de flujos económicos a partir de la matriz insumo-producto de 2008, en encuestas efectuadas en el contexto de un proyecto del Fondo Nacional de Desarrollo Regional (FNDR, 2008), y en el estudio sobre Chile y sus tipos de desarrollo (Falabella, 2000 y 2002). Finalmente, se plantea la necesidad de generar una plataforma política territorial para el desarrollo económico que facilite la rearticulación productiva.

PALABRAS CLAVE

CLASIFICACIÓN JEL

AUTORES
Desarrollo económico, desarrollo regional, industria forestal, industria de la pulpa y el papel, desarrollo industrial, estadísticas industriales, análisis de insumo-producto, Chile

$\mathrm{O} 18, \mathrm{O} 38, \mathrm{O} 43$

Gonzalo Falabella G. es académico de la Facultad de Ciencias Sociales, Departamento de Sociología, de la Universidad de Chile.mancomunal@vtr.net

Francisco Gatica N. es académico del Departamento de Economía y Finanzas de la Facultad de Ciencias Empresariales de la Universidad del Bío-Bío. fgatica@ubiobio.cl 


\section{I}

\section{Introducción ${ }^{1}$}

El título descriptivo de este artículo constituye la pregunta de la presente investigación. En esta se plantea la diferencia, por una parte, entre la capacidad hegemónica combinada de la Conurbación e industrias del Gran Concepción y de la cadena forestal-celulosa para un desarrollo conjunto; o, por el contrario, la ruptura de lo anterior. Este quiebre implica el desarrollo enclave forestal-celulosa -con las consecuencias que ello tiene en el territorio del Secano Interior de la Región del BíoBío- y la falta de encadenamiento virtuoso entre dicho enclave y el desarrollo industrial de la Conurbación. Se trata de un tema central del desarrollo regional y, como referencia, del proyecto país.

Antes de 1973, la cadena forestal-celulosa no había alcanzado la posterior expansión de su nivel económico facilitada por políticas de privatización, orientación a la exportación y fomento productivo (reforestación, subcontratación forestal sin derecho a negociación colectiva, entre otras ${ }^{2}$ ). Sin embargo, con esas políticas públicas no se logró un desarrollo regional sinérgico, caracterizado por el desenvolvimiento de la industria básica (carbón, petróleo, acero y celulosa), así como de la de consumo interno (textil, metalurgia, vidrio y cemento) y la explotación de recursos naturales de bajo costo (forestal, pesca y agrícola), combinando la propiedad estatal y privada ${ }^{3}$.

Con posterioridad a 1973 se produjo un quiebre que provocó la ruptura en el territorio entre el desarrollo

\footnotetext{
$\square$ Los autores agradecen los valiosos comentarios de la evaluación anónima de la Revista CEPAL.

${ }^{1}$ Los académicos autores de este artículo realizan investigaciones en el proyecto del Fondo Nacional de Desarrollo Científico y Tecnológico (FONDECYT) No $1130296,2013-2016$.

2 Nacimiento posee un complejo forestal de nivel mundial; sin embargo, presenta un menor desarrollo relativo. Véase Galdames, Menéndez y Yévenes (2001).

${ }^{3}$ Una interesante revisión de los diferentes modelos de industrialización y de los 100 años de políticas públicas chilenas se puede encontrar en Meller (1998). En este sentido, se tiene un tipo de desarrollo urbano y social directamente vinculado al modelo de sustitución de importaciones. El caso paradigmático de "polos productivos" es el de la Compañía Siderúrgica Huachipato y su conjunto de empresas interrelacionadas. Este entramado cambia de forma significativa con el paso de un modelo de industrialización a otro centrado en la exportación. En este contexto, la Región del Bío-Bío presenta una emergencia de las actividades exportadoras, pesqueras y forestales, que implicó una destrucción de las empresas de sustitución de importaciones y su grado de imbricación con los tejidos locales (Rojas, 1995).
}

encadenado de varios sectores y el ahora acelerado crecimiento de la cadena forestal-celulosa, en el llamado proceso de restructuración productiva (Rojas, 1995) que cambió drásticamente la geografía económica regional.

En una perspectiva de corto plazo, se avizora un desarrollo de los sectores forestal-celulosa en sí mismo "ganador". Pero deja abierta la pregunta de si se da un desarrollo vinculado a la Conurbación mediante un encadenamiento productivo virtuoso, o más bien, se repite un diagnóstico de "enclave" donde la cadena tiende a subcontratar localmente labores rutinarias o a adquirir insumos de baja complejidad, derramando pocas externalidades positivas para su entorno.

Los actores regionales no son capaces de "pensar la región" (Rojas, 2002), limitando el desarrollo conjunto. ¿Debido a qué? Debido al paso de un Estado y actores desarrollistas a otro más preocupado por el éxito de cada cadena, en un nuevo modelo liberal-exportador.

$\mathrm{El}$ aspecto frustrado del proceso fue la incapacidad de la Conurbación de aprovechar las oportunidades de desarrollar sus múltiples y consolidadas cadenas - hacia atrás, hacia adelante y lateralmente-, sobre todo en el sector acero-metalúrgico de Hualpencillo-Talcahuano y en cuanto al apoyo en ciencia y tecnología de las Universidades regionales y de la política pública estatal, aunque los fondos provenientes de la Corporación de Fomento de la Producción (CORFO) y del Fondo Nacional de Desarrollo Regional (FNDR $)^{4}$ pasaron a ser de exclusivo control regional, a diferencia del resto del país, como en los casos de Innova Bío-Bío o del Consejo Regional de Ciencia y Tecnología (CORECYT), que han servido de modelos para el resto del país (OCDE, 2010).

En estudios posteriores se ha resaltado la expansión y "chilenización" de la cadena forestal-celulosa exportadora de chips y madera de construcción, pero sin el encadenamiento productivo-metalúrgico de la celulosa brasileña, si bien Bercovich y Katz (2003) señalan en su estudio que la cadena chilena le sigue en dinamismo en la región latinoamericana.

¿Por qué Chile es presentado como el que sigue al Brasil en desarrollo regional, pero distante del continuo encadenamiento del sector forestal brasileño?

\footnotetext{
4 Véase FNDR (2008).
} 
Esta pregunta y su análisis plantean dos líneas de argumentación al desarrollo forestal chileno: i) el estímulo estatal a la privatización y exportación, sumado a un mercado mundial en expansión; y ii) a diferencia del Brasil, la ausencia en Chile de estímulo a la sustitución de exportaciones con posterioridad al golpe de Estado. Esto fue acompañado de un sistema político binominal posdictadura que produce un empate entre el gobierno y la oposición en el Congreso, lo que ha permitido expandir la liberalización de su comercio exterior mediante múltiples tratados de libre comercio, pero que ha redundado en una gobernabilidad cada día más frágil.

En resumidas cuentas, una economía conducida casi de manera única por la exportación — que destruyó su industria sustitutiva de importaciones e inhibió el desarrollo más complejo y variado de una industria forestal nacional- y un sistema político "empatado" que acentúa el actual modelo de crecimiento.

En el estudio de Bercovich y Katz (2003) se privilegia al Brasil por sobre Chile debido a la ausencia en el segundo de una industria de la celulosa de base industrial propia, como sí se generó en el caso del Brasil. En Chile se expandió la cadena forestal primaria mediante una industrialización maderera de construcción liviana (tableros, paneles, laminados y otros) y una industria de la celulosa. Pero esta última es importada y no de industrialización propia como en el Brasil, siendo, además, atendida externamente.

La hipótesis del presente trabajo, que trasciende los alcances de este informe sobre la base de los antecedentes tratados, es que hoy, entre las cadenas matrices de la Conurbación y la forestal-celulosa-madera liviana - a pesar de que cuentan con universidades desarrolladas y un gobierno regional con recursos propios (Falabella, 2002)_, se observa más que un desarrollo conjunto, un crecimiento paralelo y sin mayores alianzas virtuosas de desarrollo regional entre cadenas, gobierno y universidades.

El actor político del territorio en que se localiza el sector forestal se ha organizado en la Asociación de Municipalidades para el Desarrollo Económico Local (AMDEL), integrada por seis comunas. En ellas se intenta considerar la región desde su territorio, necesitando encadenarse al Gran Concepción, su entorno inmediato, para alcanzar su propio desarrollo (Gatica, 2008). Sin embargo, esto requiere de la contraparte del Gobierno Regional, las universidades, la Conurbación industrial del Gran Concepción y la disposición a superar su situación de enclave de las dos empresas matrices de los sectores forestal y de la celulosa.

En el artículo se destaca el vacío que existe en el desarrollo de un sector industrial de peso en Chile (ejemplificado en el caso de la Región del Bío-Bío), que le permita superar su desarrollo enclave de recursos naturales. Los nuevos procesos a partir de las tecnologías de la información y las comunicaciones (TIC), que se concentran principalmente en la Región Metropolitana, ponen de manifiesto la falta de encadenamientos económicos similares ${ }^{5}$. A ello solo se suman avances iniciales de valor agregado exportado (Muñoz, 2002), fenómeno con raíces históricas (Cardoso y Faletto, 1969; Fanjzylber, 1990) y aún extendido en América Latina (CEPAL, 2012; Ocampo, 2013).

\footnotetext{
${ }^{5}$ Hipótesis en curso de los autores: proyecto FONDECYT N ${ }^{\circ} 1130296$ acerca del aún débil desarrollo asociado de los sectores de tecnologías de la información y las comunicaciones (TIC) con las otras cadenas de la Región Metropolitana, sobre la base de datos preliminares de 70 empresas y de la matriz de insumo-producto, en especial del cuadrante de utilización intermedia total.
}

\section{¿El desarrollo de la Región del Bío-Bío es liderado por el Gran Concepción?}

\section{Con respecto al papel exportador}

En términos globales, la Región del Bío-Bío tiene una estructura exportadora altamente concentrada, donde los procesos de innovación se han centrado en dar una mayor eficiencia a las cadenas actualmente existentes alcanzando mayores economías de escala, sin que se experimente un significativo proceso de diversificación de la canasta exportadora.

Claramente, en el año 2010 el sector forestal comprendía el $77 \%$ de los principales productos de la industria exportadora regional. El resto de los productos 
no tenían un volumen significativo y solo abarcaban un $23 \%$ de las exportaciones. Ello da cuenta de una estructura de exportación sectorialmente concentrada, situación que no ha variado en sus rasgos estructurales en los últimos 20 años.

Por otra parte, aunque la Región del Bío-Bío pierde competitividad dado que representa solo un $7,2 \%$ del producto interno bruto (PIB) nacional, y la Región Metropolitana genera el 43,6\%, en diversos diagnósticos se confirma la existencia de varios núcleos científicotecnológicos en dicha región, que además disponen de capital humano avanzado (CEUR, 2010). Sin embargo, este conocimiento no ha llegado a transformar la producción regional de intensiva en recursos naturales a una estructura económica con mayor innovación y conocimiento, que estimulen un crecimiento más elevado y una menor tasa de desocupación.

Si se considera el consumo de trozas (véase el cuadro 1), el sector forestal de la Región del Bío-Bío explica el 57,2\% del total nacional, donde el 76\% del volumen regional es generado por la pulpa de celulosa $(40 \%)$ y la madera aserrada (36\%). Al comparar su peso porcentual con el del año 2004, se comprueba que la pulpa sube en importancia, en tanto que la madera aserrada baja significativamente 16 puntos porcentuales. De aquí que se tenga una "reorganización productiva" del sector, aumentando la producción de celulosa, de astillas (derivadas de la producción de pulpa y que incluye al chips) y de los tableros. En tanto que disminuyen su participación los trozos aserrables y pulpables para la exportación, los cajones y los postes y polines. La contribución regional a la producción nacional de cajones y polines es menor, del orden del 18,8\% y $33,6 \%$, respectivamente.

No obstante, la industria forestal de la Región del Bío-Bío aumentó su consumo en 1,3 millones de metros cúbicos sólidos entre los años 2004 y 2010, lo que evidencia su expansión.

Por otra parte, las exportaciones (véase el cuadro 2) indican que, en conjunto, el sector forestal-celulosaindustria de madera liviana sigue abarcando las tres cuartas partes del total regional, manteniéndose a la cabeza el sector celulosa (sobre el 30\%) desde los años noventa, que es el que distingue a Chile en América Latina, después del Brasil, pero con un componente industrial vinculado a él (maquinarias y equipos) de bajo desarrollo, a pesar de que es el sector que acompaña a la exportación con más potencial de aprendizaje y difusión tecnológica (Gatica, 2010).

En definitiva, la cadena forestal no tiene una mayor conexión productiva en el Gran Concepción, a pesar de que por sus máquinas y herramientas constituye un sector relevante a nivel regional, y que la parte más dinámica de la cadena — la pulpa-celulosa — dispone de tecnología íntegramente importada y acondicionada desde el extranjero (Katz, Stumpo y Varela, 1999).

CUADRO 1

Consumo de madera en troza según localización de la industria, 2004-2010 a

(En metros cúbicos sólidos sin corteza)

\begin{tabular}{|c|c|c|c|c|c|c|c|}
\hline & $\begin{array}{c}\text { Región del } \\
\text { Bío-Bío } 2004\end{array}$ & Porcentajes & $\begin{array}{c}\text { Región del } \\
\text { Bío-Bío } 2010\end{array}$ & Porcentajes & País en 2010 & Porcentajes & $\begin{array}{c}\text { Región/País } \\
\text { (en porcentajes) }\end{array}$ \\
\hline Pulpa & 5649869 & 30,6 & 7857973 & 39,7 & 12759465 & 36,9 & 61,6 \\
\hline Madera aserrada & 9610444 & 52,0 & 7058736 & 35,7 & 12245568 & 35,4 & 57,6 \\
\hline Tableros & 1288883 & 7,0 & 2070560 & 10,5 & 3535173 & 10,2 & 58,6 \\
\hline Astillas ${ }^{b}$ & 1585436 & 8,6 & 2669226 & 13,5 & 5656021 & 16,4 & 47,2 \\
\hline $\begin{array}{l}\text { Trozas aserrables de } \\
\text { exportación }\end{array}$ & 63061 & 0,3 & 1894 & 0,0 & 2760 & 0,0 & 68,6 \\
\hline $\begin{array}{l}\text { Trozas pulpables de } \\
\text { exportación }\end{array}$ & 119680 & 0,6 & 23852 & 0,1 & 24398 & 0,1 & 97,8 \\
\hline Cajones ${ }^{c}$ & 68674 & 0,4 & 19800 & 0,1 & 105600 & 0,3 & 18,8 \\
\hline Postes y polines ${ }^{d}$ & 86739 & 0,5 & 77579 & 0,4 & 230630 & 0,7 & 33,6 \\
\hline Total Región del Bío-Bío & 18472786 & 100,0 & 19779620 & 100,0 & 34559616 & 100,0 & 57,2 \\
\hline
\end{tabular}

Fuente: elaboración propia sobre la base de Banco Central, Indicadores económicos y sociales regionales de Chile, 1980-2010, Santiago de Chile, 2012.

a Volúmenes de madera en troza procesada en la industria maderera por región.

b Astillas provenientes de madera pulpable. La clasificación de astillas de madera incluye chips.

c Consumo de la industria cajonera que utiliza trozas para la producción exclusiva de cajones (por ejemplo, bobinadoras).

d Consumo de la industria de polines y postes (impregnados y sulfatados). 


\begin{tabular}{|c|c|c|c|c|}
\hline Producto & Julio de 2011 & Julio de 2010 & $\begin{array}{c}\text { Variación } \\
\text { (en porcentajes) }\end{array}$ & $\begin{array}{c}\text { Total julio de } 2011 \\
\text { (en porcentajes) }\end{array}$ \\
\hline Celulosa & 178,4 & 147,4 & 21,0 & 37,0 \\
\hline Madera contrachapada & 32,4 & 31,4 & 6,8 & 6,8 \\
\hline Tablero de fibra de madera & 29,6 & 20,4 & 44,8 & 6,2 \\
\hline Chips-astillas madera & 26,7 & 18,3 & 46,3 & 5,6 \\
\hline Harina de pescado & 14,2 & 40,3 & $-64,9$ & 3,0 \\
\hline Papel bobinas & 12,7 & 13,8 & $-7,9$ & 2,7 \\
\hline Jurel entero congelado & 8,0 & 4,0 & 101,9 & 1,7 \\
\hline Frambuesa, zarzamoras, moras & 6,9 & 4,0 & 73,5 & 1,5 \\
\hline Leche condensada & 5,6 & 5,8 & $-2,3$ & 1,2 \\
\hline Polietileno & 5,3 & 0,0 & - & 1,1 \\
\hline Conserva jurel & 5,0 & 3,1 & 61,0 & 1,1 \\
\hline Gasolina & 4,8 & 0,0 & - & 1,0 \\
\hline Subtotal & 403,2 & 366,7 & 9,9 & 85,1 \\
\hline Otro (plástico, caucho, etc..) & 70,5 & 57,4 & 22,9 & 14,9 \\
\hline Total & 473,6 & 424,1 & 11,7 & 100,0 \\
\hline China & Estados Unidos & Japón & Holanda & Italia \\
\hline 73,7 & 37,3 & 39,9 & 32,3 & 31,5 \\
\hline
\end{tabular}

Fuente: Instituto Nacional de Estadísticas (INE), Boletín Exportaciones Regionales, año 20, edición 201, julio de 2011.

\section{El aislamiento del Secano Interior y la respuesta política}

La Asociación de Municipalidades para el Desarrollo Económico Local (AMDEL) aglutina actualmente a seis municipalidades del Secano Interior, entre las que se encuentran Santa Juana, San Rosendo, Hualqui, Florida, Yumbel y Cabrero. Sus orígenes, en un proyecto de desarrollo productivo, son anteriores a la definición de la Estrategia de Desarrollo Regional del Bío-Bío del año 2000, donde se establecen nueve territorios de planificación como metodología de priorización del FNDR.

La mirada demográfica al año 1992 y la proyección al año 2020 permiten contrastar la heterogeneidad de crecimiento poblacional. Nítidamente, el Gran Concepción aparece como un territorio "ganador" en lo poblacional (véase el gráfico 1). En 1992 tiene unos 669.000 habitantes y las proyecciones al año 2020 lo ubican en el rango de los 872.000 habitantes. En un sentido contrario aparece el territorio del Secano Interior (conformado por los seis municipios de la AMDEL), cuya población bordeaba los 85.000 habitantes en 1992 y según las proyecciones al año 2020 se estima que llegará a 105.000 habitantes.

En el caso de la pirámide poblacional del Secano Interior, se observa una "estructura regresiva" con una fuerte migración en la población joven (de los 20 años
RECUADRO 1

\section{Surgimiento de la Asociación de Municipalidades para el Desarrollo Económico Local (AMDEL)}

En 1995, el Servicio de Cooperación Técnica (SERCOTEC), de la VIII Región, llevó a cabo el Programa de Apoyo a la Gestión Municipal de Fomento Productivo, focalizándose en el desarrollo de capacidades de las administraciones territoriales (municipalidades) para estimular la actividad económica local mediante la generación de condiciones de entorno.

Como resultado de la iniciativa, en julio de 1998 se constituyó, bajo apoyo de la Subsecretaría de Desarrollo Regional y Administrativo (SUBDERE), el Proyecto de Fomento de Municipalidades para el Desarrollo Económico Local (PROFO Municipios), integrado por las municipalidades de Coelemu, Laja, Penco, Tomé y Yumbel.

En 2001 se constituyó un nuevo PROFO Municipios, esta vez integrado por ocho municipalidades: Cabrero, Florida, Hualqui, Nacimiento, Penco, San Rosendo, Santa Juana y Yumbel. Luego de una reestructuración interna, en 2006 Penco y Nacimiento renunciaron a la Asociación de Municipalidades para el Desarrollo Económico Local (AMDEL), quedando la conformación que se mantiene hasta hoy.

Fuente: elaboración propia sobre la base de www.amdel.cl. 
GRÁFICO

\section{Población por territorio de planificación}

(Número de habitantes)

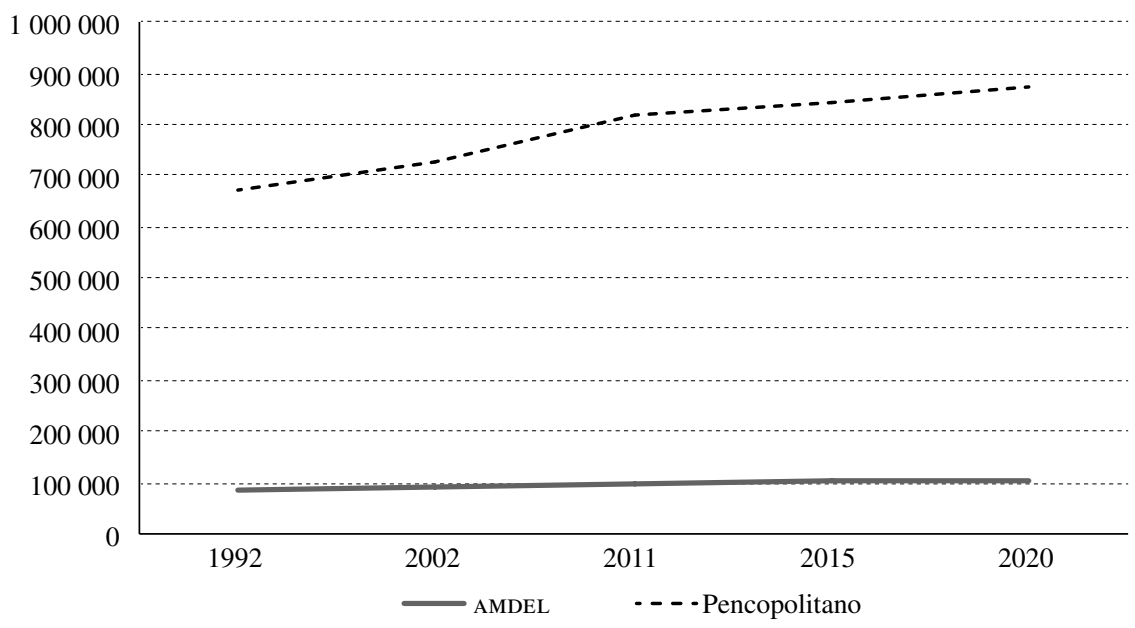

Fuente: elaboración propia sobre la base de datos del Instituto Nacional de Estadísticas (INE) y F. Gatica y A. Yévenes, "Planificación económica territorial y empleo: Análisis de las relaciones existentes entre rubros económicos priorizados en el Programa de Desarrollo Territorial y las potencialidades en la generación de empleo en la Región del Bío-Bío", Taller de Empleo Regional, ํㅜ 22, Concepción, Universidad del Bío-Bío, 2005.

AMDEL: Asociación de Municipalidades para el Desarrollo Económico Local.

GRÁFICO 2

Pirámide poblacional del Secano Interior

(Población estimada al año 2010 correspondiente a las municipalidades de la AMDEL)

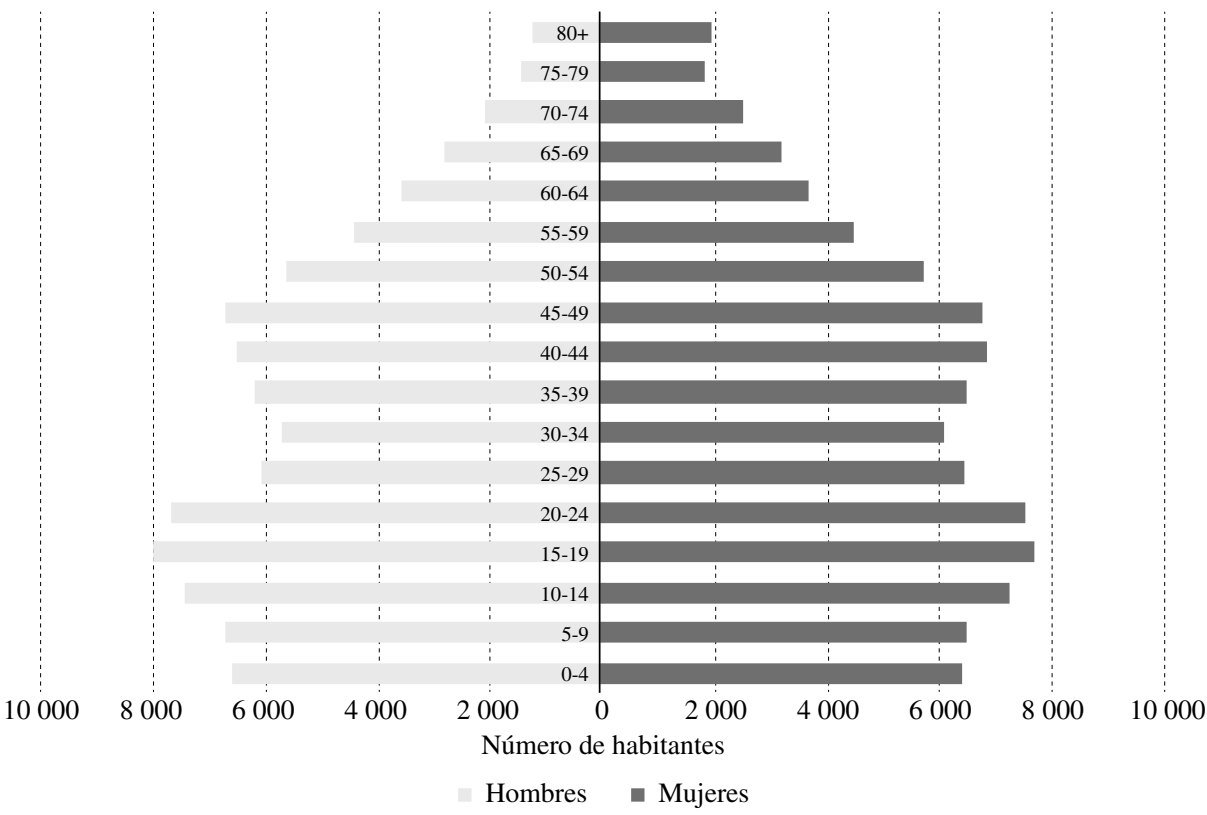

Fuente: elaboración propia sobre la base de pirámides de población, datos del Instituto Nacional de Estadísticas (INE) y F. Gatica y A. Yévenes, "Planificación económica territorial y empleo: Análisis de las relaciones existentes entre rubros económicos priorizados en el Programa de Desarrollo Territorial y las potencialidades en la generación de empleo en la Región del Bío-Bío", Taller de Empleo Regional, $\mathrm{N}^{\circ} 22$, Concepción, Universidad del Bío-Bío, 2005.

AMDEL: Asociación de Municipalidades para el Desarrollo Económico Local. 
a los 45 años) y una contracción en la presencia de niños y jóvenes menores de 15 años de acuerdo con la tendencia nacional. En definitiva, se aprecia un menor crecimiento de la población, con una relación de 1:9, donde por cada habitante del Secano Interior hay nueve habitantes del Gran Concepción. Este antecedente ha sido desequilibrante en el momento de priorizar proyectos de inversión pública intrarregional.

De este modo, los datos refuerzan el diagnóstico de la "mejor posición relativa" del territorio Pencopolitano ${ }^{6}$ o del Gran Concepción. En principio, su ingreso autónomo (sin subsidio del Estado) es un $41 \%$ más alto que el promedio regional y registra una menor proporción de población indigente. En el caso de las comunas del Secano Interior, eminentemente forestales, se comprueba que el ingreso autónomo es un tercio menor que el del Gran Concepción, y la población indigente

${ }^{6}$ Se llama territorio Pencopolitano debido a que la primera fundación de la ciudad de Concepción se hizo en la actual ciudad de Penco, a orillas del Océano Pacífico, debiendo cambiarse a consecuencias del maremoto de 1570 . Pese a esto, el gentilicio quedó vinculado al primer emplazamiento.

\section{III}

\section{Metodología}

Se procura identificar las redes económicas alrededor del sector forestal y, en paralelo, visualizar los flujos económicos entre el Gran Concepción y el Secano Interior.

\section{Primer eje: matriz de insumo-producto alrededor del sector forestal}

Para identificar el grado de conexión productiva alrededor del sector forestal con el resto de las cadenas productivas, se trabaja con la matriz de insumo-producto construida por el Banco Central de Chile (2008), en especial con el cuadrante de utilización intermedia nacional (precios de usuarios).

Cabe consignar que se opera con la matriz nacional y que existen diferencias de perfiles de compra que pueden variar de región en región. Hoy no se cuenta con una matriz regionalizada actualizada ${ }^{7}$. Sin embargo, tal

\footnotetext{
7 Actualmente, existe una matriz de insumo-producto regional, que es una proyección en que se utiliza el método RAs, que permite
}

es notoriamente superior al promedio regional según se da cuenta en distintos informes de la Unidad de Gestión de Información Territorial (UGIT, s/f).

Frente a esta asimetría, se deduce que la riqueza de la Conurbación no ha estimulado el desarrollo del Secano Interior, donde se concentra la cadena exportadora forestal-celulosa. Los vasos comunicantes no son lo suficientemente robustos, generándose un "desarrollo dual" en el territorio (conjunto forestal/Conurbación).

Incluso este "desarrollo dual" se da en el interior de la AMDEL y más específicamente en la comuna de Nacimiento, donde opera el complejo industrial forestal Santa Fe de la Compañía Manufacturera de Papeles y Cartones (CMPC). Esta comuna presentaba tasas de desocupación de un 15,3\% en el año 2000, de un $11,5 \%$ en 2003 , de un $11,6 \%$ en 2006 y de un 15,2\% en 2009, sobre la base de la Encuesta de Caracterización Socioeconómica Nacional (CASEN). Lo anterior da cuenta "de un mercado laboral deprimido y del impacto de la crisis mundial" (Municipalidad de Nacimiento, 2012), en particular del efecto negativo en los encadenamientos productivos y el empleo de la industria de la celulosa allí concentrada (Galdames, Menéndez y Yévenes, 2001).

como se mencionó, el sector forestal de la Región del Bío-Bío explica el 57\% del consumo de trozas a nivel nacional. Por lo tanto, no debería haber una diferencia significativa entre la matriz de insumo-producto nacional y la regional (por construirse), salvo debido a la "fuga de compras" de algunas adquisiciones que van de la industria forestal regional a proveedores especializados en la capital nacional.

$\mathrm{Al}$ respecto se analiza:

- el porcentaje de compras realizadas por cada subsector forestal. Se procura identificar cuál subsector tiene mayor nivel de vinculación o encadenamiento hacia atrás. Lo anterior a partir

contar con una visión aproximada de los flujos comerciales de una región, a partir de la matriz nacional generada en 1996 (Pino y Parra, 2011). En tal sentido, los procesos de innovación pueden explicar el surgimiento de nuevas líneas de productos y actividades. En resumen, pese a que la matriz no está regionalizada, su valor consiste en que es una fotografía actualizada de una actividad que está concentrada en las regiones VII, VIII y IX del país. 
de volúmenes de compras, sin importar el tipo de vínculo en términos de agregación de valor;

- la distribución de las compras por parte del sector forestal y el nivel de dedicación de las ventas. Se identifican los principales insumos vendidos al sector forestal y se calcula qué porcentaje de sus ventas está completamente dedicado a satisfacer las necesidades de este sector. Esta mirada permite deducir el tipo de relación que se tiene con el entorno económico, $\mathrm{y}$

- la distribución de compras por actividades. En el fondo se procura identificar el "eslabón principal hacia atrás" por subsector forestal. Lo anterior permite visualizar el tejido productivo que se construye a partir de cada subsector, identificando la relación entre la agregación de valor y el tipo de compra que se realiza.

\section{Segundo eje: flujos económicos entre el Gran Concepción y el Secano Interior}

Mediante financiamiento del FNDR se levantaron encuestas de origen y destino a las unidades agrícolas, a las familias, a la micro, pequeña y mediana producción y a diferentes unidades de paisaje ${ }^{8}$ en el interior de las comunas de la $\mathrm{AMDEL}^{9}$ para identificar los circuitos

\footnotetext{
${ }^{8}$ El concepto de unidad de paisaje (UP) se refiere a todo aquello que aparece en forma homogénea ante la vista. En el fondo es una división subcomunal, instrumental para fines de análisis, con la que se procura recoger zonas que por motivos geográficos, históricos, productivos y de identidad, entre otros aspectos, generan una unidad homogénea en su interior y distinta respecto del resto.
}

económicos locales. A partir de estos resultados se analizan los principales encadenamientos hacia adelante por cada unidad de paisaje. Hay que consignar que este análisis no sigue una lógica sectorial-tradicional, sino que plantea un enfoque territorial, identificando cuáles son los patrones geográficos de determinadas redes de productos.

Se analizan dos planos:

- $\quad$ se genera una representación gráfica mediante los principales flujos económicos del Secano Interior, a partir de la cual se identifican tres tipos de redes: i) tipo árbol: donde todos los flujos económicos se dirigen a la capital regional; ii) tipo eje: aquellas que se estructuran alrededor de los caminos, y iii) tipo estrella: en que una actividad en el territorio centraliza los flujos económicos. La identificación de estos patrones sirve como guía de orientación de las políticas públicas en el territorio, y

- $\quad$ se individualiza para cada comuna el principal producto demandado por el Gran Concepción. Se identifican los principales flujos de mano de obra, forestal, productos agrícolas y servicios turísticos. Para cada caso se sugiere una línea de desarrollo de cara a una política pública.

Esta es una primera aproximación, debido a que no se cuenta con información completa disponible que permita dimensionar íntegramente la relación entre cadena productiva y territorio. En consecuencia, la superposición final entre ambas dimensiones será analítica y se orientará a generar políticas públicas para reencadenar los tejidos productivos.

\footnotetext{
9 Véase Gatica (2008).
}

\section{Estudio de campo}

\section{Relaciones de insumo-producto alrededor de la cadena forestal}

La revisión de la matriz de insumo-producto de 2008 —véase el cuadro 3- para los sectores que pueden ser clasificados como forestales evidencia que la fabricación de celulosa es la actividad que ocupa la mayor cantidad de insumos nacionales, explicando un $29 \%$ de las compras principalmente de energía. En un segundo nivel de importancia se encuentran los aserraderos y la acepilladura de maderas, donde los volúmenes de compra son del $20 \%$, destacándose sobre todo la compra de madera sin procesar. En un tercer nivel se hallan la actividad silvícola, con un $17 \%$ de las compras, y la fabricación de productos de madera que demanda un $15 \%$ de los insumos nacionales; en este último caso, el 28,5\% de sus compras son subproductos de la misma cadena.

Se observa nítidamente un menor nivel de demanda de insumos por parte de los sectores de mayor nivel agregado, lo que se relaciona directamente con el 
CUADRO 3

\section{Porcentaje de compras realizadas por cada subsector}

\begin{tabular}{lc}
\hline Actividad & Porcentajes \\
\hline Silvicultura y extracción de madera & 17 \\
Aserrado y acepilladura de maderas & 20 \\
Fabricación de productos de madera & 16 \\
Fabricación de celulosa & 29 \\
Fabricación de envases de papel y cartón & 6 \\
Fabricación de otros artículos de papel y cartón & 6 \\
Fabricación de muebles & 6 \\
Total compras intrasectoriales & 100 \\
& \\
Porcentaje de las compras sectoriales sobre el total de & 5,1 \\
compras de los productos involucrados en la cadena & \\
\hline $\begin{array}{l}\text { Fuente: elaboración propia sobre la base de Banco Central de Chile, } \\
\text { "Matriz de insumo-producto de 2008" [en línea] www.bcentral.cl }\end{array}$ \\
$\begin{array}{l}\text { Nota: se elabora a partir del cuadrante de utilización intermedia } \\
\text { nacional (precios de usuarios). }\end{array}$
\end{tabular}

volumen de actividad. En este sentido, los envases de papel y cartón, los otros artículos de papel y los muebles explican cada uno un $6 \%$ de las compras nacionales. En esta última actividad, las compras principales son servicios generales y subproductos de la cadena.

Como conclusión, se constata el desnivel en la demanda de insumos nacionales entre las industrias productoras de productos básicos industriales y aquellas que tienen un mayor nivel de diferenciación, lo que se vincula al volumen de actividad, condicionando el encadenamiento que ejerce esta actividad con respecto al resto de la economía local.

Por último, todas las compras del sector forestal, a nivel nacional, representan un 5,1\%. En este sentido, hay un flujo de insumos que no es valorizado, que se da en el interior de la cadena integrada verticalmente. Estas transacciones intracadena son especialmente intensas en los complejos forestales, donde las empresas procuran reducir los riesgos de operación internalizando los procesos desde los bosques hasta la venta final.

En principio, el insumo más importante son los recursos naturales que explican el 30,9\% de las compras del sector (véase el cuadro 4). Para estos insumos su grado de dedicación o focalización es relativamente alto, donde el 68,3\% de las ventas están orientadas a la industria forestal. En un segundo rango de importancia están los subproductos o transacciones intracadena, cuyas ventas se dirigen al sector forestal en un $16,3 \%$, con un grado de focalización relativamente menor $(33,5 \%)$.

En resumen, las transacciones de recursos naturales e intracadena explican el 47,2\% de las compras del sector forestal. Lo que también es un indicador de complejidad productiva, evidenciando un tipo de actividad que tiende a generar redes de producción poco complejas a su alrededor.

Este diagnóstico coincide con la concentración de la actividad en dos grandes grupos económicos, Celulosa Arauco y Constitución (CELCO) y Compañía Manufacturera de Papeles y Cartones (CMPC), con un alto grado de integración vertical. Dado que la operación de estos dos grupos productivos se localiza fundamentalmente en la Región del Bío-Bío, el uso de la matriz insumo-producto nacional es pertinente para deducir eslabonamientos principales al nivel regional. La industria forestal que se ubica en las regiones VII, IX y X sigue el mismo patrón, primando la homogeneidad por sobre la probabilidad de que aparezca una actividad emergente.

En un segundo nivel de importancia se encuentra el eslabón energía, que explica un 14,7\% de los insumos, y los servicios generales que representan el $14,8 \%$ de las

CUADRO 4

\section{Distribución de las compras por parte del sector forestal y grado de focalización de las ventas}

Principales productos vendidos a la industria forestal

Insumos primarios: coníferas, eucaliptus, otros productos silvícolas

Subproductos o transacciones intracadena: madera aserrada, prensada, celulosa, envases

Energía: gasolina, gas, electricidad

Productos químicos: plaguicidas, plásticos, otros productos químicos

Productos de hierro y acero e instalación de máquinas y equipos

Transportes de carga, ferrocarril, puertos y almacenamiento

Servicios generales: financieros, seguros, inmobiliarios, alquiler,

informáticos, jurídicos y contables, ingeniería, otros

Otros insumos, bienes y servicios

Total de insumos para la cadena forestal
Compras del sector forestal (en porcentajes)

Dedicación (porcentajes de ventas a la industria forestal/ total de la economía)

Fuente: elaboración propia sobre la base de Banco Central de Chile, "Matriz de insumo-producto de 2008" [en línea] www.bcentral.cl

Nota: se elabora a partir del cuadrante de utilización intermedia nacional (precios de usuarios). 
compras; en este caso se identifica un bloque amplio: finanzas, seguros, inmobiliarias, alquiler, informática, jurídicos, contables e ingeniería, donde el grado de focalización de estos productos hacia el sector forestal es relativamente menor y va desde el $5,5 \%$ en la energía al $2,7 \%$ en los servicios.

Finalmente, existen insumos que tienen una baja importancia para la cadena, entre los que se encuentran los químicos, los del hierro y el acero y otros productos. En este caso, el peso sobre las ventas oscila de un 5,5\% a un $3,9 \%$, respectivamente.

Hay que consignar que un bajo grado de focalización de las ventas en un sector específico limita la capacidad de generar procesos de aprendizaje interactivo, condicionando el desarrollo de la aglomeración productiva (cluster) a partir de una cadena principal o clave. Por lo tanto, se deben trabajar con mayor nivel de detalle las subclasificaciones de la matriz, información que no existe actualmente, identificando el grado de focalización.

En el cuadro 5 se aprecian las principales compras para cada actividad en el interior de la cadena forestal. Un elemento de análisis interesante es la identificación del eslabón principal hacia atrás. En principio, se identifican:
- $\quad$ Actividad silvícola: el 82,6\% de las compras se vincula a insumos primarios como coníferas y eucaliptus. De todas las actividades, es la que presenta la mayor concentración de sus insumos. Hay que considerar que casi la totalidad de las comunas analizadas en este estudio presentan esta realidad productiva.

- Actividad de aserraderos: el eslabonamiento principal hacia atrás está dado por los insumos primarios $(46,3 \%)$. Sin embargo, se observa una mayor diversidad de compras. Se destacan los subproductos intracadena $(19,1 \%)$, los servicios de transporte $(14,3 \%)$ y los servicios generales $(12,8 \%)$.

- Fabricación de productos de madera: donde el encadenamiento principal hacia atrás son los subproductos de la misma cadena $(28,5 \%)$. En un segundo nivel se encuentran los servicios generales que explican el $22,7 \%$ de las compras.

- Fabricación de celulosa: aquí se observa un cambio; el eslabón principal hacia atrás es la energía $(32,9 \%)$ y en un segundo lugar se halla el insumo primario (20\%). Cabe destacar que en esta producción los niveles de integración vertical hacia atrás son

CUADRO 5

Distribución de las compras por actividad

(En porcentajes)

\begin{tabular}{|c|c|c|c|c|c|c|c|}
\hline & $\begin{array}{l}\text { Silvicultura } \\
\text { y extracción } \\
\text { de madera }\end{array}$ & $\begin{array}{l}\text { Aserrado y } \\
\text { acepilladura } \\
\text { de maderas }\end{array}$ & $\begin{array}{l}\text { Fabricación } \\
\text { de productos } \\
\text { de madera }\end{array}$ & $\begin{array}{l}\text { Fabricación } \\
\text { de celulosa }\end{array}$ & $\begin{array}{c}\text { Fabricación } \\
\text { de envases } \\
\text { de papel y } \\
\text { cartón }\end{array}$ & $\begin{array}{l}\text { Fabricación } \\
\text { de otros } \\
\text { artículos } \\
\text { de papel y } \\
\text { cartón }\end{array}$ & $\begin{array}{l}\text { Fabricación } \\
\text { de muebles }\end{array}$ \\
\hline $\begin{array}{l}\text { Insumos primarios: coníferas, } \\
\text { eucaliptus, otros productos silvícolas }\end{array}$ & 82,6 & 46,3 & 12,8 & 20,0 & 0,0 & 0,0 & 1,3 \\
\hline $\begin{array}{l}\text { Subproductos o transacciones } \\
\text { intracadena: madera aserrada, } \\
\text { prensada, celulosa, envases }\end{array}$ & 0,3 & 19,1 & 28,5 & 9,4 & 49,6 & 16,2 & 20,3 \\
\hline $\begin{array}{l}\text { Energía: gasolina, gas, } \\
\text { electricidad }\end{array}$ & 5,0 & 4,8 & 10,7 & 32,9 & 6,6 & 16,7 & 3,3 \\
\hline $\begin{array}{l}\text { Productos químicos: plaguicidas, } \\
\text { plásticos, otros productos químicos }\end{array}$ & 3,8 & 0,3 & 6,9 & 6,8 & 10,0 & 6,0 & 12,2 \\
\hline $\begin{array}{l}\text { Productos de hierro y acero e } \\
\text { instalación de máquinas y equipos }\end{array}$ & 3,3 & 0,5 & 2,6 & 4,3 & 1,7 & 11,2 & 12,3 \\
\hline $\begin{array}{l}\text { Transportes de carga, ferrocarril, } \\
\text { puertos y almacenamiento }\end{array}$ & & 14,3 & 14,2 & 13,9 & 7,3 & 10,1 & 7,9 \\
\hline $\begin{array}{l}\text { Servicios generales: financieros, } \\
\text { seguros, inmobiliarios, alquiler, } \\
\text { informáticos, jurídicos y contables, } \\
\text { ingeniería, otros }\end{array}$ & 2,9 & 12,8 & 22,7 & 10,6 & 20,2 & 36,0 & 26,4 \\
\hline Otros insumos, bienes y servicios & 2,1 & 2,0 & 1,7 & 2,0 & 4,7 & 3,9 & 16,1 \\
\hline $\begin{array}{l}\text { Total de insumos para la cadena } \\
\text { forestal }\end{array}$ & 100,0 & 100,0 & 100,0 & 100,0 & 100,0 & 100,0 & 100,0 \\
\hline
\end{tabular}

Fuente: elaboración propia sobre la base de Banco Central de Chile, "Matriz de insumo-producto de 2008” [en línea] www.bcentral.cl

Nota: se elabora a partir del cuadrante de utilización intermedia nacional (precios de usuarios); en gris, los principales vínculos hacia atrás, sobre el $20 \%$. 
mayores, constatándose una alta concentración de la producción en dos grandes grupos empresariales, CELCO y CMPC.

- Fabricación de envases de papel y cartón: nuevamente se observa una estructura concentrada donde el vínculo principal hacia atrás, dado por los subproductos de la cadena, explica el 49,6\% de las compras. Muy por debajo están los servicios generales con un $20,2 \%$ de las compras.

- Fabricación de otros productos de papel: una actividad "atípica" cuya principal compra son los servicios generales. Conviene consignar que toda esta actividad explica solo el $6 \%$ de las compras totales del sector.

- Fabricación de muebles: tiene un bajo peso en los montos globales transados (6\% del total) y presenta como encadenamiento principal hacia atrás los servicios generales, explicando un $26,4 \%$ de las compras. Su mayor valor agregado hace que el ítem otros insumos, bienes y servicios explique el $16,1 \%$ de sus compras, lo que escapa a lo observado en las otras actividades.

Sobre la base de estos primeros antecedentes, se evidencia que el emplazamiento y desarrollo de la cadena forestal no presenta encadenamientos. Tres son los rasgos que determinan, en este caso, el desarrollo del binomio cadena-territorio.

- Concentración en dos compañías y reducción de la variedad productiva. Un elemento que condiciona las posibilidades de desarrollo es la alta concentración de la propiedad del suelo en dos grandes compañías (más de 2 millones de hectáreas). Lo anterior dificulta los procesos de diversificación (por ejemplo, la industria del mueble). El actual marco de incentivos apunta al desarrollo concéntrico hacia atrás de la cadena de valor, permitiendo el mayor control de la propiedad del bosque. De esta forma se alcanzan economías de escala con bajos riesgos de operación. Su extensión ha sido al sector energético (Colbún) y forestal exterior, y no de encadenamiento industrial con una mayor demanda por desarrollo tecnológico local.

- Lejanía de los espacios de diálogo. Debido a la alta concentración en la propiedad de la empresa forestal, se produce una mayor lejanía entre los actores territoriales y la gerencia de la empresa ubicada en la capital nacional. Esto dificulta la posibilidad de generar una articulación públicoprivada a nivel territorial.

- Asimetrías en las posiciones estratégicas en función de la parte de la cadena de valor más cotidiana. La percepción que tiene cada habitante está condicionada por la "parte" o el eslabón de la cadena que le es más cotidiana. A consecuencia de ello se pierde la visión sistémica en el momento de implementar políticas para el sector en el territorio. En general, en las intervenciones se desconocen las diferentes inserciones que tienen las comunas en un circuito superior de acumulación. De aquí que sea compleja la vinculación de territorios globales y dinámicas de negociación territoriales.

Por lo tanto, en un mismo territorio y en una misma actividad se evidencian cuatro tipos de desarrollo: i) se encuentran "enclaves" con una muy baja capacidad de difusión en el territorio; ii) se identifican procesos de "desencadenamiento" en las antiguas redes agrícolas a raíz de la expansión forestal (Guerrero, 2012); iii) se observa un "desarrollo dual" entre la gran empresa que pertenece a los grupos CMPC y CELCO, y los pequeños aserraderos independientes, y iv) existe la posibilidad de desarrollar un "centro potencial" que, por la vía de la innovación, genere nuevas redes que conecten a estos enclaves con el tejido productivo local.

\section{Fuerza gravitacional del Gran Concepción sobre las redes económicas del Secano Interior de la Región del Bío-Bío}

\section{a) Fuerza gravitacional y Secano Interior}

El Gran Concepción es un sistema urbano estructurado, con una clara división del trabajo en su interior (Hernández, 1982) producto de su historia, la que fue marcando las fuerzas estructurantes de su desarrollo ${ }^{10}$. En las últimas décadas se destacan dos procesos:

- La reestructuración productiva, en los términos desarrollados en la primera parte de este trabajo, que implicó tener en el mismo espacio ciudades con industrias llamadas "emergentes" — vinculadas a la exportación - y otras contenedoras de industrias llamadas "decadentes", orientadas sobre todo al consumo interno (Rojas, 1995). Se debe recordar que la Conurbación fue depositaria de polos productivos de envergadura nacional. Específicamente en Talcahuano-Hualpén se encuentra la instalación del complejo petroquímico (Petrox) y la Compañía

10 La construcción histórica del sistema urbano tiene algunos elementos del enfoque evolucionista (véase Fischer, 2009), donde los sistemas actuales son el resultado de una combinación entre variedad y selección de la mejor rutina generada en la historia. Una visión biológica de la estructura territorial permite entender los procesos de reconstrucción, la definición de límites-fronteras y el análisis de redes, entre otros elementos. 
Siderúrgica Huachipato. Conviene subrayar que estas industrias generaron una red de proveedores en el sector metalmecánico y de mantención industrial, y asimismo, se implementaron urbanizaciones para que vivieran los trabajadores y se instalaran los servicios sociales (por ejemplo, clubes deportivos, entre otros).

En los años ochenta se produce la llamada "inserción fácil" — basada en un tipo de cambio elevado y recursos naturales de bajo costo-y en los años noventa se identifica la profundización del modelo exportador mediante la firma de múltiples tratados de libre comercio (TLC).

De este modo, se consolida en la Conurbación el diagnóstico inicial de los años setenta (Hernández, 1982), en que algunas comunas presentan actualmente tasas de desocupación que superan largamente la media nacional. Se destaca Coronel con una tasa de desocupación del 10,4\%, Lota con un 9,8\% y Talcahuano con una tasa de desempleo de un $8,9 \%$ (trimestre móvil mayo-julio de 2011 (INE, 2011b)). Hay que consignar que la tasa de desocupación nacional es de un $7,5 \%^{11}$, manteniéndose las comunas mencionadas con un desempleo estructural sostenido durante casi dos décadas.

- Se aprecia un cambio en las especializaciones económicas, donde hay una reconversión en el papel de las ciudades en el interior de la Conurbación: i) Penco, Coronel y Lota pasan de comunas industriales depositarias de fábricas sustitutivas a ser "ciudades dormitorio"; ii) Concepción se mantiene como centro decisional, y iii) San Pedro de la Paz, no obstante ser una comuna nueva, asume un papel mixto de ciudad dormitorio y plataforma de servicios. No obstante, la Conurbación - que va desde Lota al sur hasta Tomé por el norte en el borde costero- es una unidad de análisis vigente, que demanda una manera distinta de entender las políticas públicas que actúan en este territorio. Adquiere importancia un gobierno metropolitano, que supere a una comuna individual y que sea menor que el espacio regional. De esta manera, una institucionalidad en este nivel resulta clave en temáticas como red de transporte, planificación territorial, sistema de salud y educación.

En este punto se procura identificar de qué forma la fuerza gravitacional ejercida por el Gran Concepción atrae a los flujos económicos de las comunas, sobre todo forestales del Secano Interior, agrupadas en la AMDEL, y

11 Véase INE (2011b). cómo su incorporación puede ser relevante para diseñar las políticas públicas en el territorio.

En definitiva, las fuerzas gravitacionales originadas por la Conurbación también serán estructurantes del territorio de la AMDEL y afectarán a los flujos económicos, generando externalidades positivas y negativas en procesos como el cambio en la factibilidad de algunos negocios, ya sea por la proximidad a los mercados de venta; la mayor presión que se tiene sobre algunos factores productivos (por ejemplo, el suelo o los recursos naturales); la deslocalización de algunas empresas debido a los costos de localización que obligan a su traslado ${ }^{12}$; el creciente fenómeno de las "segundas residencias" que redundan en una población flotante, y el incremento de la tendencia a la migración del campo a la ciudad, entre otros procesos.

\section{b) Tejer redes económicas para difundir el desarrollo ${ }^{13}$}

En el estudio de los circuitos económicos locales para el Secano Interior se identificaron los principales flujos por medio de encuestas aplicadas a las familias, a los predios agrícolas, a la micro y pequeña producción y al origen-destino. El estudio se realizó a nivel de espacios intracomunales (unidades de paisaje), y se preguntó por los flujos anuales que tienen algún valor comercial.

En principio, cuando se grafican los principales flujos económicos del Secano Interior (AMDEL) se identifica la influencia que ejerce el Gran Concepción en las ventas generadas en este territorio.

Asimismo, se reconoce una zona que recibe la mayor influencia de la fuerza gravitacional ejercida por la Conurbación. Dicho espacio abarca una parte importante de las comunas de Santa Juana y Hualqui, y afecta parcialmente a la comuna de Florida. En definitiva, la mayor cercanía geográfica al Gran Concepción genera externalidades vinculadas a la apertura de nuevos mercados y movilidad de la mano de obra.

En este contexto, se observan comunas que no están tan directamente influenciadas por el Gran Concepción, como es el caso de Yumbel, San Rosendo y Cabrero. En estos casos hay redes económicas dirigidas a la Conurbación, pero los flujos relevantes apuntan en otra dirección.

\footnotetext{
12 Se trata de empresas, intensivas en costo, que al crecer comienzan a enfrentar mayores dificultades para expandir sus plantas, lo que afecta a sus economías de escala. A esto se agrega una mayor presión - derivada de un mayor tráfico y contaminación-para deslocalizar de los negocios a algunas zonas periféricas (Méndez, 1999).

13 En este punto se trabaja con un extracto de los resultados del FNDR (2008).
} 
Una mayor abstracción de los flujos que vinculan a ambos territorios permite deducir tres grandes tipos de redes:

i) Redes tipo árbol: son aquellas que apuntan al Gran Concepción y en las que, en términos espaciales, los eslabones de la cadena se pueden localizar en diferentes lugares geográficos del territorio con una lógica agregadora de valor. Por ejemplo: el flujo de la miel cuya producción puede encontrarse en la zona rural de alguna comuna del Secano Interior, pero su proceso de envase puede situarse en la capital comunal y, finalmente, su mercado de destino está en el Gran Concepción.

En tal sentido, la política pública mediante la transferencia de tecnología y organización puede estimular la articulación de las cadenas en el

Principales redes económicas a nivel de unidades paisajísticas (UP)

(Territorios agrupados en la AMDEL)

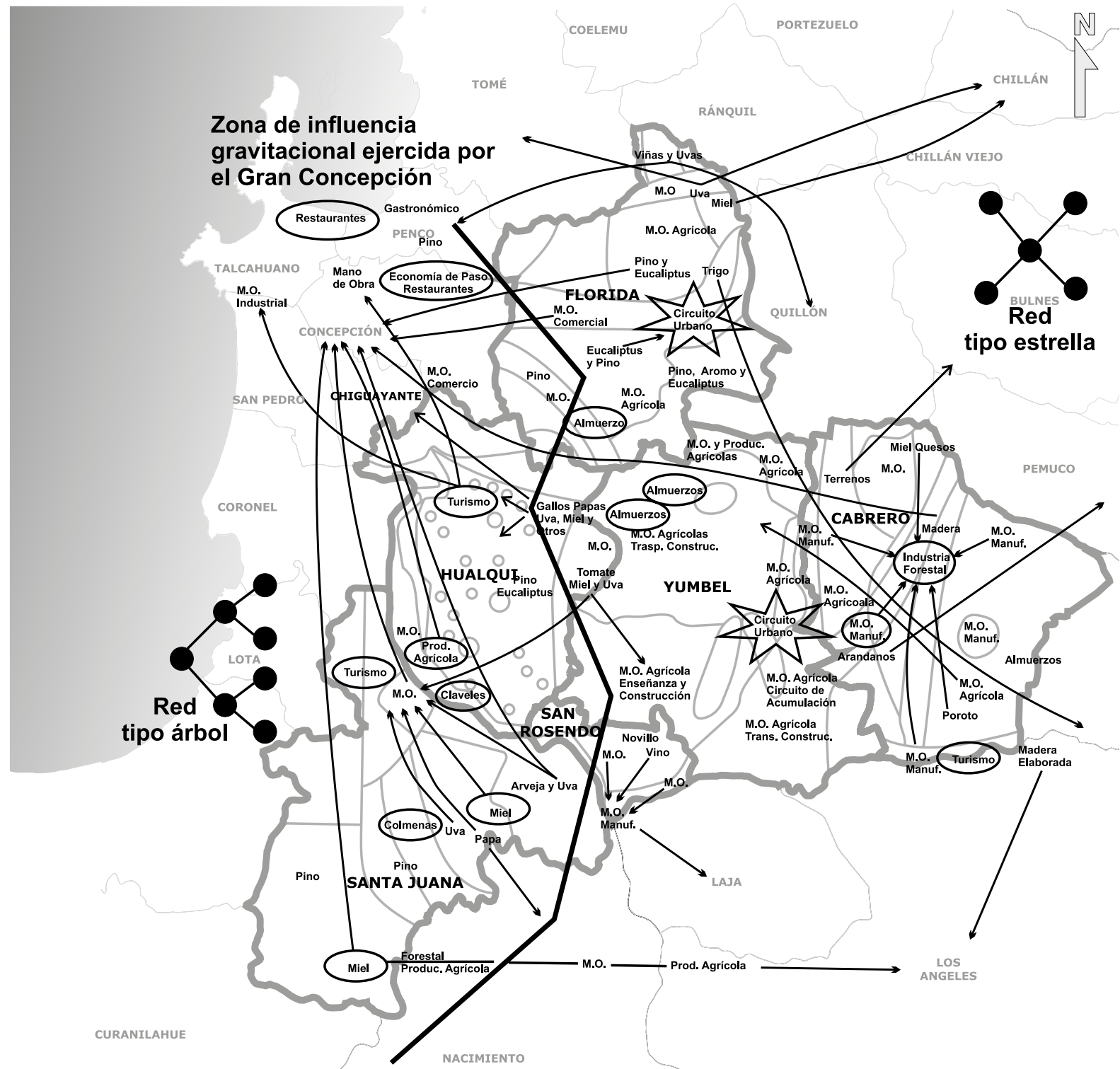

Fuente: elaboración propia a partir de los resultados del proyecto Fondo Nacional de Desarrollo Regional (FNDR) "Estudio Básico de los Circuitos Económicos Locales BIP 20179020-0”. Gobierno Regional de la Región del Bío-Bío.

AMDEL: Asociación de Municipalidades para el Desarrollo Económico Local. 
territorio con sus diferentes eslabones, para llegar con un mayor valor agregado a la Conurbación. La riqueza de un territorio siempre se puede difundir sobre la base de mejoras en la competitividad de la producción local, no así por la mera reorientación de las ventas a los demás sectores, la que suele llamarse en Chile "teoría del chorreo".

ii) Redes tipo estrella: estas muestran una clara centralidad de los flujos económicos en el territorio, sin que operen nodos intermedios. En este caso se encuentran las redes económicas que se generan alrededor de Cabrero urbano. En su dimensión territorial se pueden asemejar a un ejemplar de company town.

En este caso se deben aprovechar estos polos para desarrollar "pirámides productivas" (Scott, 1998), donde a partir de la empresa madre — como es el complejo forestal— se generan nuevos tejidos productivos con empresas que satisfacen al sector principal, gestándose valiosos procesos de aprendizaje interactivo; pero además se pueden establecer relaciones de venta con otros sectores productivos dando lugar a un sector "pivote" del desarrollo.

iii) Redes tipo eje: son aquellas que se producen o se estructuran alrededor de los caminos, constituyéndose en una fuerza que permite articular las cadenas agrícolas dentro del Secano Interior. Así, las iniciativas públicas pueden estimular la salida de los productos por medio de la localización de puntos de ventas, que tengan identidad y permitan atraer a los viajeros.

Sin embargo, también por estos ejes transita cotidianamente la mano de obra, en especial la de la zona de Florida, Hualqui y Santa Juana. El territorio asume un papel de proveedor de mano de obra (poco calificada) para el Gran Concepción. Son trabajadores que siguen viviendo en las comunas del Secano Interior, pero que una parte de sus compras familiares las realizan en el comercio local.

Por ello, una iniciativa de política pública consiste en que esta fuerza del trabajo local, con instrumentos focalizados, pueda incrementar sus competencias laborales, de tal forma que al aumentar sus salarios se estimule la demanda local.

Una mirada más precisa de la redes en ambos territorios se obtiene del cuadro 6. En primer lugar, se comprueba la relevancia que tiene el flujo de mano de obra. Casi todas las comunas del Secano Interior son proveedoras de trabajo para el Gran Concepción. Se destaca también la alta variedad de sectores. Se aprecia una mano de obra dedicada a los servicios personales, y otras dirigidas a la actividad comercial, del transporte $y$, finalmente, a la manufactura.

Los tipos de red árbol, estrella y eje son orientadores de las políticas públicas en el territorio. Sirven de guías que permiten conectar mejor la oferta de productos o servicios con el interior del territorio de la AMDEL y de estos con la demanda proveniente del Gran Concepción en rubros como: mano de obra, forestal, agrícola y turismo. Es una mirada más "micro" de la economía, que permite reencadenar los tejidos productivos corrigiendo el tipo de "desarrollo dual".

En conclusión, las comunas del Secano Interior, más que únicas proveedoras de productos agrícolas para el Gran Concepción, son oferentes de mano de obra, pese a las distancias entre las cabeceras comunales y la capital regional ( 1 a 2 horas de viaje en locomoción colectiva).

Un segundo tipo de flujo económico se vincula a la cadena forestal en sus fases silvícola y manufacturera. Actualmente se constata un movimiento de pino radiata y eucaliptus desde Hualqui y Florida con destino al Gran Concepción.

En el caso de Cabrero se debe destacar una producción de mayor grado de elaboración: la remanufactura que produce tableros, aglomerados, enchapados, puertas, entre otros. En este caso sobresale la venta de madera impregnada al Gran Concepción (orientada a la construcción). Una parte importante de la producción del complejo forestal localizado en Cabrero se dirige a la exportación.

Evidentemente se requiere una política activa que vincule a la cadena forestal con el territorio. En el interior del secano, la percepción que se tiene de la cadena forestal depende del tipo de actividad que específicamente se localiza en la comuna. La percepción de los habitantes donde está instalada la planta forestal es diferente de la de aquellos que solo conviven con la actividad silvícola (bosques y camiones). Por consiguiente, es clave vincular la cadena forestal y su heterogeneidad con los diferentes territorios.

En este sentido, para el desarrollo del Secano Interior es clave que el Gran Concepción sea una cabecera competitiva dentro de un posible cluster forestal. La prioridad consistiría en la creación de una industria de la celulosa con base industrial chilena o un consorcio (joint-venture) con capitales externos. Hoy esta industria es importada y mantenida en su totalidad desde el exterior. Paradójicamente, el desarrollo inicial de capacidades productivas en Nacimiento se deterioró en el tiempo a raíz de la importación de insumos y repuestos para las plantas de celulosa (Galdames, Menéndez y Yévenes, 2001). 


\begin{tabular}{|c|c|c|c|}
\hline Producto & $\begin{array}{l}\text { Comuna de } \\
\text { origen }\end{array}$ & Flujo principal & $\begin{array}{l}\text { Línea de desarrollo de cara a una } \\
\text { política pública }\end{array}$ \\
\hline $\begin{array}{l}\text { Mano } \\
\text { de obra }\end{array}$ & $\begin{array}{l}\text { Florida } \\
\text { Hualqui } \\
\text { Hualqui } \\
\text { Santa Juana } \\
\text { San Rosendo } \\
\text { Yumbel } \\
\text { Florida } \\
\text { Hualqui }\end{array}$ & $\begin{array}{l}\text { Mano de obra comercial } \\
\text { Mano de obra comercial } \\
\text { Mano de obra dedicada a los servicios personales (empleadas } \\
\text { domésticas y servicios de aseo) } \\
\text { Mano de obra dedicada a los servicios personales } \\
\text { Mano de obra dedicada al transporte } \\
\text { Mano de obra dedicada al transporte } \\
\text { Mano de obra dedicada a los servicios personales y comerciales } \\
\text { Mano de obra manufacturera }\end{array}$ & $\begin{array}{l}\text { Mejora de los circuitos locales de la } \\
\text { AMDEL en la medida en que mejoran las } \\
\text { competencias laborales y los ingresos de } \\
\text { la mano de obra local que va a trabajar } \\
\text { al Gran Concepción, activando las } \\
\text { compras locales. }\end{array}$ \\
\hline Forestal & $\begin{array}{l}\text { Florida } \\
\text { Hualqui } \\
\text { Cabrero }\end{array}$ & $\begin{array}{l}\text { Pino radiata y eucaliptus } \\
\text { Pino radiata y eucaliptus } \\
\text { Pino radiata, eucaliptus y madera elaborada (incluye secado } \\
\text { e impregnado) }\end{array}$ & $\begin{array}{l}\text { Necesidad de que el Gran Concepción } \\
\text { sea polo innovador de la cadena } \\
\text { forestal. Coexistencia con actividad de } \\
\text { convivencia con el bosque. } \\
\text { Actualmente, Cabrero se constituye en } \\
\text { un núcleo industrial. }\end{array}$ \\
\hline $\begin{array}{l}\text { Producto } \\
\text { agrícola }\end{array}$ & $\begin{array}{l}\text { Santa Juana } \\
\text { San Rosendo } \\
\text { Florida } \\
\text { Hualqui } \\
\text { Yumbel }\end{array}$ & $\begin{array}{l}\text { Productos agrícolas (arveja, uva, papa y miel) } \\
\text { Productos agrícolas (membrillo, ciruela, durazno) } \\
\text { Productos agrícolas (uva blanca) } \\
\text { Productos agrícolas (uvas tintas y blancas, miel, gallinas, claveles) } \\
\text { Productos agrícolas (vino tinto) }\end{array}$ & $\begin{array}{l}\text { Articulación de las cadenas agrícolas } \\
\text { para llegar al Gran Concepción con } \\
\text { mayor valor agregado. } \\
\text { Aprovechamiento de las "condiciones } \\
\text { de paso" alrededor de los caminos para } \\
\text { articular cadenas agrícolas. }\end{array}$ \\
\hline Turismo & $\begin{array}{l}\text { Hualqui } \\
\text { Santa Juana }\end{array}$ & $\begin{array}{l}\text { Actividad turística (piscinas) } \\
\text { Actividad turística (camping a orillas del Rio Lía) }\end{array}$ & $\begin{array}{l}\text { Organización y mejoramiento de los } \\
\text { empresarios locales. Capacidad de } \\
\text { generar circuitos turísticos competitivos. }\end{array}$ \\
\hline
\end{tabular}

Fuente: elaboración propia a partir de los resultados del proyecto Fondo Nacional de Desarrollo Regional (FNDR) "Estudio Básico de los Circuitos Económicos Locales BIP 20179020-0”. Gobierno Regional de la Región del Bío-Bío.

AMDEL: Asociación de Municipalidades para el Desarrollo Económico Local.

En el caso de la producción agrícola, se observa una alta dispersión de productos y de orígenes; la excepción es Cabrero donde no se observan flujos agrícolas relevantes que se dirijan al Gran Concepción. En términos generales, se identifican productos como uvas blancas, uvas tintas, frutales, miel, claveles, entre otros. Su relevancia es que permiten alimentar a una parte de la población de la Conurbación (de escasos recursos, que no compra en supermercados, sino en ferias informales), pero además es parte fundamental de los ingresos de las familias, en especial de la zona de agricultura clásica, con suelos gastados y con un fuerte desfase tecnológico.

En buenas cuentas, en el Secano Interior se tiene la posibilidad de transferir tecnologías, pero más importante aún es la capacidad de organizar la cadena productiva dirigida al Gran Concepción.

Por último, está la actividad turística y recreativa que se genera alrededor del Gran Concepción, donde el Secano Interior recibe visitantes. En esta actividad destaca Hualqui, donde hay piscinas y diferentes zonas de camping funcionando incluso como un proyecto de fomento. Por otra parte, está la comuna de Santa Juana que cuenta con camping a orillas del Rio Lía y piscinas en las cercanías de la capital comunal. La política pública debe orientarse a organizar a los empresarios locales y al mejoramiento de los estándares de calidad, identificando diferentes circuitos turísticos conectados con operadores y clientes institucionales del Gran Concepción (por ejemplo, adultos mayores, servicios de bienestar de las empresas, cajas de compensaciones, entre otros).

\section{Un necesario "bucle"14 de refuerzo para el desarrollo económico territorial}

El Secano Interior puede desarrollarse en la medida en que el Gran Concepción, y específicamente su ciudad cabecera, se inserte de manera competitiva, con innovación y 14 El concepto de "bucle" se entiende como una "cadena cerrada de
causa-efecto". La idea proviene del pensamiento sistémico donde "todas
las partes del sistema están conectadas directa o indirectamente, de
modo que al cambiar una de las partes el efecto se propaga a todas las
demás, que experimentan un cambio y, a su vez, termina afectando a
la parte original. Así pues, la influencia vuelve modificada a la parte
original, lo que genera un bucle" (véase O'Connor y McDermott, 1998). 
sostenibilidad, en los flujos económicos globales — siendo una ciudad atractiva para la localización de inversiones más complejas e inclusivas-, encadenando la cadena forestal-celulosa-fabricación liviana de madera con la industria productora de maquinaria industrial, lo que favorece los circuitos de acumulación en la Conurbación.

De cumplirse lo anterior, la mayor riqueza de la capital provincial se difunde al territorio del Secano Interior por medio de las diferentes redes económicas — tipo árbol, eje y estrella—, las que en su mayoría responden a relaciones de compra-venta de productos agrícolas, turismo, flujo de mano de obra o a la sola condición de paso del flujo vehicular.

De este modo, la difusión de la riqueza no solo pasa por la existencia de redes económicas con las comunas del Secano Interior, sino que también es fruto de un mejoramiento en las competencias tecnológicas, productivas y organizativas en este territorio para conectarse virtuosamente con la Conurbación.

En este contexto se distinguen dos cuellos de botella que se deben superar para la nivelación de competencias y la generación de redes que difundan el desarrollo al nivel territorial:

- El marcado centralismo intrarregional al nivel de la acción pública. El ser vecino de una conurbación produce, en los "hacedores de política", una ceguera en la jerarquización de los proyectos, que se explica por diferentes presiones electorales (número de votos), desconfianzas en las capacidades de los equipos territoriales, presencia de grupos de influencia y ausencia de un claro control social sobre los "decididores y ejecutores" de la inversión, entre otros problemas (Lahera, 2008).

- La distancia entre los gerentes de las empresas que están en el territorio con respecto a los diferentes gestores municipales y actores sociales locales. Este no es un factor solamente geográfico, sino que también se refiere a brechas en el manejo de tecnologías y lógicas de desarrollo, lo que aleja a la Región del Bío-Bío -depositaria de las plantas productivas- y su entorno de la dirección económica central de la capital nacional.

Si se superan estos "cuellos de botella" de centralismo intrarregional público y privado, se tendrá una relación virtuosa y más competitiva con la Conurbación, lo que conllevará la localización de nuevas empresas en el Secano Interior a partir de las redes tipo árbol, eje y estrella que de allí surjan y de una ramificación productiva a partir de nuevos productos de complejidad creciente, generados por diferentes procesos de innovación (vésase el diagrama 1). A ello se podría sumar el estímulo del Gobierno Regional a la instalación de nuevos negocios en la Conurbación y el regreso de las universidades a su antiguo activo de desarrollo regional. Este proceso es un "bucle" de refuerzo positivo donde se exige una visión sistémica del desarrollo (O'Connor y McDermott, 1998), con iniciativas de políticas públicas acotadas - pero con un sentido estratégico- que pueden tener un "efecto palanca" que gatille positivamente el desarrollo eslabonado.

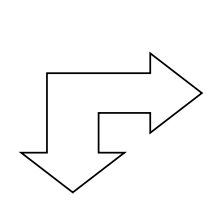

Gran Concepción con gobierno, cienciatecnología y empresarios que atraen y estimulan la innovación y el emprendimiento alrededor de la cadena forestal, a escala global
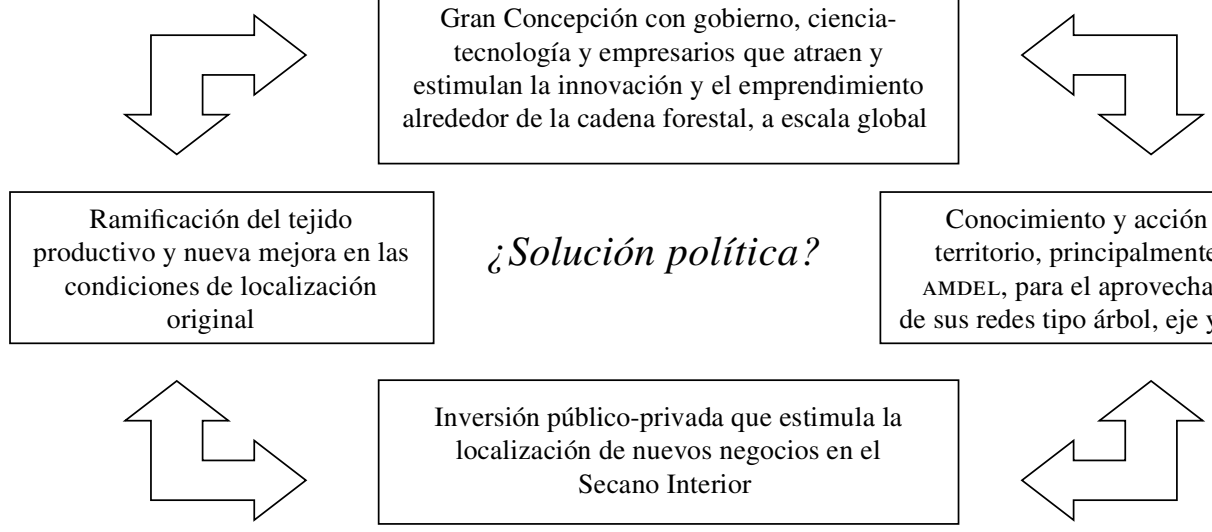

Conocimiento y acción en el territorio, principalmente en la AMDEL, para el aprovechamiento de sus redes tipo árbol, eje y estrella

Fuente: elaboración propia.

AMDEL: Asociación de Municipalidades para el Desarrollo Económico Local. 


\section{V}

\section{Conclusión: desencadenamiento y política}

En dos estudios territoriales, Falabella (2000 y 2002) plantea una definición regional centrada en el papel de la intercomuna Concepción-Talcahuano y su extensión entre Lota y Tomé, como eje de un "encadenamiento potencial" regional mediante el cual se subraya el vacío presentado en este trabajo, pero se deslinda una potencialidad que también atañe a este estudio. El desarrollo es potencial y aún no logrado debido al abandono de una política proindustrial en Chile y a la existencia de tres actores matrices fuertes, "en trayecto paralelo", pero que aún no se encuentran: i) Gobierno Regional de mayor autonomía del país; ii) cadenas exportadoras robustas (entre las que ciertamente sobresale la forestal), y iii) un sistema de universidades regionales extensas, de peso y desconectadas entre sí (OCDE/Banco Mundial, 2010). En el estudio se enfatiza el vacío de encadenamiento industrial regional como posible expresión de un nudo nacional.

La apuesta de este trabajo es que al desarrollar la organización de la sociedad civil económica (a partir de la AMDEL) se puede empezar a revertir la falta de encadenamiento territorial con el Gran Concepción. Para ello se requiere un aporte político mayor -necesario, como la reforma política del sistema binominal-, la participación y la descentralización que faciliten el encauce de los dos grupos económicos matrices al desarrollo integral del país; en este caso, el desarrollo forestal-celulosa, en otros casos, el desarrollo agroindustrial, el minero o la salmonicultura.

En este trabajo se han identificado los principales flujos que permiten conectar la Conurbación y el territorio del Secano Interior. En consonancia con ello, las políticas públicas tienen que propender a la disminución de las brechas que se producen entre ambos territorios. En la argumentación teórica y empírica planteada en este estudio se establece claramente que la sola fuerza del mercado, junto con un Estado que implementa políticas neoliberales ortodoxas, provoca un aumento de las diferencias territoriales. Incluso la apuesta discrecional del Estado chileno de apoyar — por la vía del DL 701—al sector forestal integrado principalmente por grandes conglomerados, profundizó la desconexión con los tejidos locales y generó externalidades negativas que dificultaron el desarrollo de otras actividades productivas alternativas (por ejemplo, el encarecimiento de factores productivos como el suelo para destino agrícola, la energía o el uso de infraestructura).
En este contexto, la AMDEL se transforma en una plataforma política que permite ejercer presión con miras a descentralizar el poder de decisión en el interior de la región y el país, llegando directamente con proyectos al circuito de decisión ministerial. Es en este espacio mesoeconómico donde se tiene una visión integral de procesos que pueden afectar a varias comunas, debiéndose trabajar intersectorialmente e implementando economías de escala y enfoques de las diferentes políticas públicas. La elección por vez primera de consejeros regionales puede redundar en un aliado principal, así como el cambio del sistema electoral binominal que produce un empate en el Parlamento desde el regreso de la democracia en 1990. Lo anterior, junto con la mayor participación ciudadana, la descentralización y la rendición de cuentas (accountability) aseguran, mediante la cercanía a los problemas y el control social, que las políticas públicas puedan responder mejor a los desafíos del territorio.

Hasta ahora, la relación que se da entre la Conurbación y el Secano Interior ha sido la de "un matrimonio mal avenido"; sin embargo, en la medida en que ambos tejan redes competitivas, el desarrollo de un territorio puede "arrastrar al otro". La trayectoria de estas comunas no será del tipo agrícola tradicional, sino de un reencadenamiento que para concretarse necesita un nivel distinto de organización política, como se señala en la literatura de alianza público-privada (Devlin y Moguillansky, 2009).

Para que el Gran Concepción se inserte en los flujos globales, se requiere un gobierno metropolitano que no responda a la división tradicional de región y provincia y a la mera demanda de la cadena forestal global. Esto es aún más relevante en el caso de la Conurbación. No obstante, para que este grupo de comunas se desarrolle se necesita tener un nuevo espacio de influencia. Los habitantes de la capital regional van a las comunas del Secano Interior, compran sus productos, tienen sus segundas residencias y disfrutan de la tranquilidad del campo. Todo esto puede hacer atractiva a la metrópolis para captar capital humano calificado y con ello nuevos proyectos empresariales.

La AMDEL es una creación sociopolítica nueva como espacio asociativo; ella sigue una trayectoria que va del diagnóstico económico-territorial al instrumento de cambio para avanzar en un desenvolvimiento sinérgico 
y armónico. Su vía al desarrollo está por delante y para impulsarlo son fundamentales sus alianzas políticas regionales y nacionales, así como el apoyo en los conocimientos técnicos (know-how) de las universidades a objeto de romper el desencadenamiento forestal-celulosa del Secano Interior con la industria de la Conurbación del Gran Concepción.
Los vacíos de la industrialización tratados en este artículo —el eslabón perdido del desarrollo chileno post 1973-, junto con el posterior auge exportador de recursos naturales y el reciente impulso de cadenas ricas en tecnologías de la información y las comunicaciones (TIC), son el tema central del desarrollo regional y necesitan un proyecto país que se construya desde los territorios.

\section{Bibliografía}

Aghón, G., F. Alburquerque y P. Cortés (2001), "Desarrollo económico local y descentralización en América Latina: Un análisis comparativo" (LC/L.1549), Santiago de Chile, Comisión Económica para América Latina y el Caribe (CEPAL).

Ahumada, J. (1958), En vez de la miseria, Santiago de Chile, Editorial del Pacífico.

Banco Central de Chile (2012), Indicadores económicos y sociales regionales de Chile, 1980-2010, Santiago de Chile.

(2008), "Cuentas nacionales de Chile. Compilación de referencia 2008" [en línea] http://www.bcentral.cl/ publicaciones/estadisticas/actividad-economica-gasto/aeg 15b.htm.

Bercovich, N. y J. Katz (eds.) (2003), El desarrollo de complejos forestales en América Latina, Santiago de Chile, Comisión Económica para América Latina y el Caribe (CEPAL)/ Alfaomega.

Cardoso, F. y E. Faletto (1969), Dependencia y desarrollo en América Latina, México, D.F., Siglo XXI.

CEPAL (Comisión Económica para América Latina y el Caribe) (2012), "Política industrial", Cambio estructural para la igualdad. Una visión integrada del desarrollo (LC/G.2524(SES.34/3)), Santiago de Chile.

CEUR (Centro de Estudios Urbano Regionales) (2010), "Oferta, demanda y prospectiva de ciencia y tecnología en la Región del Bío-Bío", Estudios Regionales, № 32, Concepción, Universidad del Bío-Bío.

Devlin, R. y G. Moguillansky (2009), Alianzas público-privadas para una nueva visión del desarrollo (LC/G.2426-P), Santiago de Chile, Comisión Económica para América Latina y el Caribe (CEPAL). Publicación de las Naciones Unidas, $\mathrm{N}^{\circ}$ de venta: S.09.II.G.52.

Falabella, G. (2002), “'Se agotó el modelo?”, Repensar el desarrollo chileno. País, territorio, cadenas productivas, G. Falabella y R. Galdames (eds.), Concepción, Ediciones Universidad del Bío-Bío.

(2000), "Los cien Chile. Más allá del país promedio. Estudio exploratorio" (LC/R.2020), Santiago de Chile, Comisión Económica para América Latina y el Caribe (CEPAL).

Fanjzylber, F. (1990), "Industrialización en América Latina: De la "caja negra' al "casillero vacío", Cuadernos de la CEPAL, $\mathrm{N}^{\circ} 60$ (LC/G.1534/Rev.1-P), Santiago de Chile, Comisión Económica para América Latina y el Caribe (CEPAL). Publicación de las Naciones Unidas, $\mathrm{N}^{\circ}$ de venta: S.89.II.G.5.

Fischer, A. (2009), La mejor idea jamás pensada, Santiago de Chile, Ediciones B.

FNDR (Fondo Nacional de Desarrollo Regional) (2008), "Estudio básico de circuitos económicos locales BIP 20179020-0", Gobierno Regional de la Región del Bío-Bío.

Galdames, R., J. Menéndez y A. Yévenes (2001), “¿Tiene futuro Nacimiento? Una visión paradigmática del desarrollo local", Estudios Regionales, $\mathrm{N}^{\circ} 21$, Concepción, Universidad del Bío-Bío.
Gatica, F. (2010), "Redes locales y aprendizaje interactivo: El caso de la industria de apoyo exportador de la región del Bío-Bío, Chile", Ciudad y Territorio. Estudios Territoriales, $\mathrm{N}^{\circ} 163$, Madrid, Ministerio de Fomento.

(2008), Redes y oportunidades de desarrollo: El caso de los circuitos económicos locales en el Secano Interior de la Región del Bío-Bío, Concepción, Universidad del Bío-Bío.

Gatica, F. y A. Yévenes (2005), "Planificación económica territorial y empleo: Análisis de las relaciones existentes entre rubros económicos priorizados en el Programa de Desarrollo Territorial y las potencialidades en la generación de empleo en la Región del Bío-Bío", Taller de Empleo Regional, № 22, Concepción, Universidad del Bío-Bío.

Guerrero, R. (2012), El ocaso de una sociedad campesina. La Cordillera de la Costa en la Región de Concepción, Concepción, Universidad del Bío-Bío.

Hernández, H. (1982), "El Gran Concepción: Desarrollo histórico y estructura urbana. Primera parte. Génesis y evolución: De las fundaciones militares a la conurbación industrial", Informe Geográfico de Chile, $\mathrm{N}^{\circ} 30$.

INE (Instituto Nacional de Estadísticas) (2011a), Boletín Exportaciones Regionales, año 18, edición 201, julio.

(2011b), Boletín de empleo. Nueva Encuesta Nacional de Empleo: noviembre 2011-enero 2012, año 3, edición 23.

(s/f), "Territorio AMDEL. Antecedentes regionales" [en línea] http://ugit.gorebiobio.cl/?wpfb_dl=79.

Katz, J., G. Stumpo y F. Varela (1999), "El complejo forestal chileno", Santiago de Chile, Comisión Económica para América Latina y el Caribe (CEPAL).

Lahera, E. (2008), Introducción a las políticas públicas, Santiago de Chile, Fondo de la Cultura Económica.

Larraín, G. (2005), Chile, fértil provincia. Hacia un Estado liberador y un mercado revolucionario, Santiago de Chile, Editorial Debate.

Meller, P. (1998), Un siglo de políticas públicas, Santiago de Chile, Editorial Andrés Bello.

Méndez, R. (1999), "La estructura territorial del sistema productivo", Lecciones de economía española, J.L. García Delgado (ed.), Madrid, Civitas.

Municipalidad de Nacimiento (2012), “Actualización PLADECo Comuna de Nacimiento 2012-2015" [en línea] http:// transparencia.nacimiento.cl/index.php/actos-sobre-terceros? id=261:pladeco.

Muñoz, O. (2002), Comentario sobre "Casillero vacío del fomento productivo chileno", Repensar el desarrollo chileno. País, territorio, cadenas productivas, G. Falabella y R. Galdames (eds.), Concepción, Ediciones Universidad del Bío-Bío.

O'Connor, J. e I. McDermott (1998), Introducción al pensamiento sistémico, Barcelona, URANO.

Ocampo, J. (2013), "La arquitectura financiera mundial y regional a la luz de la crisis", serie Macroeconomía del Desarrollo, $\mathrm{N}^{\circ} 131$ (LC/L.3584), Santiago de Chile, Comisión Económica para América Latina y el Caribe (CEPAL). 
OCDE (Organización de Cooperación y Desarrollo Económicos)/Banco Mundial (2010), La Región del Bío-Bío Chile [en línea] http:// www.oecd.org/edu/imhe/47159873.pdf.

Pino, O. y J.C. Parra (2011), “Aproximación a la estructura económica de la Región del Bío-Bío en base a aplicaciones insumosproducto, para el año 2006 y base 2003", Revista Horizontes Empresariales, año 10, $\mathrm{N}^{\circ}$ 1, Concepción, Facultad de Ciencias Empresariales, Universidad del Bío-Bío.

Porter, M. (1999), Ser competitivo: Nuevas aportaciones y conclusiones, Bilbao, Ediciones Deusto S.A.

Rojas, C. (2002), "Institucionalidad para el aprendizaje. Las industrias vitivinícola y maderera del Maule", Repensar el desarrollo chileno. País, territorio, cadenas productivas, G. Falabella y R. Galdames (eds.), Concepción, Ediciones Universidad del Bío-Bío.

(1995), "El desarrollo después de la crisis del Estado del bienestar. Sus posibilidades en el caso de Concepción, Chile", Cuadernos del ILPES, $\mathrm{N}^{\circ}$ 41, Santiago de Chile, Instituto Latinoamericano y del Caribe de Planificación Económica y Social.

Scott, A.J. (1998), Regions and the World Economy: The Coming Shape of Global Production, Competition, and Political Oxford, Oxford University Press.

UGIT (Unidad de Gestión de Información Territorial) (s/f) [en línea] http://ugit.gorebiobio.cl/?page_id=70. 